\title{
The Latent Digital Divide and Its Drivers in E-Learning among Bangladeshi Students during the COVID-19 Pandemic
}

\author{
Md Badiuzzaman ${ }^{1, *}$, Md. Rafiquzzaman ${ }^{2}(0)$ Md Insiat Islam Rabby ${ }^{3}$ and Mohammad Mustaneer Rahman ${ }^{4}$ \\ 1 Faculty of Arts Design and Architecture, University of New South Wales, Sydney, NSW 2052, Australia \\ 2 Department of Industrial Engineering \& Management, Khulna University of Engineering \& Technology, \\ Khulna 9203, Bangladesh; rafiqbitr@yahoo.com \\ 3 Department of Mechanical Engineering, Universiti Putra Malaysia, Selangor 43400, Malaysia; \\ insiatislam8@gmail.com \\ 4 School of Information and Communication Technology, University of Tasmania, Hobart, TAS 7005, Australia; \\ mustaneer.rahman@gmail.com \\ * Correspondence: badiuzzaman@unsw.edu.au; Tel.: +880-1911788766
}

Citation: Badiuzzaman, M.;

Rafiquzzaman, M..; Rabby, M.I.I.;

Rahman, M.M. The Latent Digital

Divide and Its Drivers in E-Learning among Bangladeshi Students during the COVID-19 Pandemic. Information 2021, 12, 287. https://doi.org/ $10.3390 /$ info12080287

Academic Editor: Adel Ben Youssef

Received: 14 June 2021

Accepted: 30 June 2021

Published: 21 July 2021

Publisher's Note: MDPI stays neutral with regard to jurisdictional claims in published maps and institutional affiliations.

Copyright: (c) 2021 by the authors. Licensee MDPI, Basel, Switzerland. This article is an open access article distributed under the terms and conditions of the Creative Commons Attribution (CC BY) license (https:// creativecommons.org/licenses/by/ $4.0 /)$

\begin{abstract}
The devastating COVID-19 pandemic forced academia to go virtual. Educational institutions around the world have stressed online learning programs in the aftermath of the pandemic. However, because of insufficient access to Information Communication Technology (ICT), a substantial number of students failed to harness the opportunity of online learning. This study explores the latent digital divide exhibited during the COVID-19 pandemic while online learning activities are emphasised among students of Bangladesh. It also investigates the digital divide exposure and the significant underlying drivers of the divide. In order to accomplish this, a cross-sectional survey was employed to collect quantitative data, mixed with open-ended questions were utilised to gather qualitative information from the student community. The findings revealed that despite the majority of students having physical access to ICT, only $32.5 \%$ of students could attend online classes seamlessly. In total, $34.1 \%$ reported data prices as the critical barrier, while $39.8 \%$ identified poor network infrastructure as the significant barrier preventing them from participating in online learning activities. Although most students possess physical access to various devices and the Internet, they face the first-level digital divide due to the quality of access and price of cellular Internet. Consequently, they fail to take advantage of physical access, resulting in the third-level digital divide (utility gap), which submerges them into a digital divide cycle. The primary objective of this study is to explore the underlying issues of the digital divide among Bangladeshi students. This will assist relevant stakeholders (e.g., the Bangladesh government, educational institutions, and researchers) to gain necessary insights and theoretical understanding of underlying limitations and emergent directions to arrange adequate support for underprivileged students to undertake essential online learning activities.
\end{abstract}

Keywords: COVID-19; digital divide; online learning; multi-level digital divide

\section{Introduction}

At the beginning of 2020, the COVID-19 infection had spread worldwide and turned into a global endemic [1]. Many people worldwide are being infected every day, and the highly infectious nature of these viruses has created a global pandemic. On 8 March, 2020, the first case of COVID-19 was identified in Bangladesh, and until now, around 896,770 people have already been infected [2,3]. Since March 2020, the government of Bangladesh has kept all physical activities in educational institutes closed [4]. Due to the restrictions on physical classes, many educational institutes started online teaching and learning activities. However, insufficient access to ICT (information and communication technology) became a significant concern among the student community in Bangladesh. The disparity of ICT access is defined as the digital divide. 
The term "digital divide" addresses the uneven distribution of digital technology and ICT regarding usage, access, and impact in individuals' lives as well as in the activities of organisations or countries. Between the late 1980s and the early 1990s, the digital divide was an informal phrase delineating the gap between "information-rich" and "informationpoor". After the public deployment of the Internet, the gap was visible as to who did or did not have access [5]. Lloyd Morrisett coined the term to indicate a gap between socioeconomic groups in accessing technology tools [6]. The National Report on Telecommunications and Information Administration, "Falling through the Net: Defining the Digital Divide," describes the digital divide as the differences in access to telephones, personal computers (PCs), and the Internet among some demographic groups [6]. Nowadays, there is the possibility of a digital divide between any number of individuals, organisations, or countries.

Similarly, there is digital inequality among schools or student communities [7]. The notion of the digital divide is not limited to having or not having access to ICT in the 21st century. For more than two decades, extensive research on the digital divide has established multiple levels of the phenomenon concerning access to devices and the Internet, ICT usage abilities, and usage outcomes [8-12]. During the 1990s, the first digital divide research focused on access to digital technology and the Internet. Earlier, the criterion to define the difference was having access or not having access. It was a binary term restricted between two states.

Nevertheless, the binary notion is no longer appropriate. In recent years, multiple levels of the digital divide have been exposed, and each level has different layers. Theoretical experts in the digital divide field have identified three levels. According to recent studies, the first level divide is the difference in physical access to the Internet and devices; the second level is the gap in digital skills and motivation (usage gap), and the third level is the gap in the benefits from usages [11-13]. Different levels of digital division have been identified and sustain for different periods. Additionally, contemporary studies have developed complex notions of disparity at each level [14]. The first-level divide-physical access - was focused on from 1995 to 2003, the second-level divide-skills and use-was centred in 2004, and the third-level divide-outcomes of usages-was still under consideration in 2012 [15]. According to a recent theory, quality of access and the ability to maintain sustainable access are different layers of the first-level digital divide [16].

Many studies have established the level of income as an essential determinant of ICT access opportunities [17-24]. These studies found a link between the amount of income and access to ICT. They asserted that a higher income level increases the ability to access ICT. Similarly, lower income contributes to less opportunity. Therefore, people from developing countries with lower income levels will have less access to devices, promoting the digital divide at the first level. Consequently, the student community from these countries experiences the digital divide while they have to have access to ICT for educational purposes. Among all the drivers of the digital divide, income level, educational attainment, and urbanisation are the most crucial. $[25,26]$. As a result, Bangladesh's student community is vulnerable in regard to arranging adequate access to ICT, as it has a lower per capita income and lower Internet penetration rate with significantly lower internet speed $[27,28]$.

A UN policy brief on "Education During COVID-19" stated that the COVID-19 pandemic is the largest disruption of education systems in human history, affecting approximately 1.6 billion learners worldwide [22]. According to the study, an average of $94 \%$ of learners worldwide were affected by the devastating consequences of the COVID-19 pandemic. Among them, around 99\% are poor and primarily belong to lower-middle-income nations. Schools went into a sudden shutdown due to health concerns; governments from several countries responded quickly and switched to online learning. In developed countries, $80-85 \%$ of learners gained online learning coverage [22]. Disappointingly, less than $50 \%$ of students in low-income countries could access online learning [22]. Since the onset of the COVID-19 outbreak, the government of Bangladesh has suspended face-to-face learn- 
ing activities at educational institutions and began online learning activities. Although the government has initiated several remote learning arrangements (e.g., instructions through Radio, Television, and e-learning), students lacking adequate access to ICT will likely be deprived of e-learning activities.

Furthermore, there is a scarcity of research on the impact of the digital divide on e-learning activities in the Bangladeshi context amid the pandemic. Hence, we probed the latent digital divide in Bangladesh during exacerbated ICT enable learning activities while the pandemic forced institutes to go online. The study revealed significant facts that depict the existence of digital inequality among the Bangladeshi student community and explain the accounted variables. Additionally, we identified that the first-level digital divide results in a third-level divide and forming a vicious cycle. The findings will help the policymakers and respective stakeholders to rethink and redesign the e-learning activities. Additionally, the study will help to undertake necessary fundamental initiatives to reduce the digital divide. Conceivably, the COVID-19 crisis exposed the untold story of the digital divide in Bangladesh, and this study illustrated the complex scenario of the multi-level digital divide.

Many Bangladeshi newspapers questioned the effectiveness of entirely onlinedependent learning during the lengthy closure of educational institutes. They also anticipated this may cause significant number of students' exclusion from the e-learning opportunities [23]. However, no report or study has explained the issues from the theoretical perspective of the multi-level digital divide. Therefore, we formulated the research questions to address the issues and analysed the data based on the theory of multidimensional digital divides [24].

\section{Research Question}

Although ICT incorporation has introduced an unprecedented way to interact in education, there is a high possibility that ICT-enabled learning activities will introduce barriers to many students in Bangladesh due to the disparity in access to ICT. Likewise, students may experience an amplified digital divide during the exacerbated online learning activities. The study formulated two research questions to address the issue:

- $\quad$ RQ1: What is the scenario of the digital divide among Bangladeshi students during the COVID-19 pandemic while they need to participate in online learning activities?

- RQ2: If the digital divide is found in RQ1, then what are the key drivers?

\section{Literature Review}

The term "digital divide" has become an indicator to measure ICT access status in developing countries [25]. Empirical evidence exhibits that developing countries are confronting severe inequalities accessing ICT. Pick et al. examined the geographical and socioeconomic pattern of adaptation, diffusion, and ICT usages pattern in 36 nations of LAC (Latin American and the Caribbean [26]. The LAC has 10.5\% of world internet users, and the internet penetration has reached $71.5 \%$ in 2020 , which seems progressive. Nonetheless, inequalities in the adoption and use of digital technology exist in LAC countries [27]. Authors claimed that prosperous LAC nations had two times more internet penetration rates than impoverished nations. Another large-scale study of 161 nations discovered a region-specific explanation for the disparity in ICT adoption [27]. The study demonstrated that the digital divide is primarily caused by income differential. Similarly, numerous studies have identified income levels as the dominant driver of the digital divide. Therefore, students from LDCs with low per capita income are likely to face the digital divide in an ICT-enabled learning environment.

Along with the conventional digital divide, rising inequality like algorithmic capitalism has become a significant concern in developing countries [28]. Algorithmic capitalism refers to cyber capitalism or the spectacular growth of ICT ventures (e.g., Google, Microsoft, Amazon). Karar states that information capitalism was the third generation of capitalism after mercantilism and the industrial revolution [28]. Developing countries are likely to 
encounter emerging inequalities during the application of ICT for many aspects of daily life. For instance, after analysing a sizable national quantitative dataset, Tewathia et al. provided insight into the relation between India's digital disparity and social inequalities [29]. They employed Marxian perspectives and revealed the influence of ICT ownership and ICT skills on higher labour class status. The study also applied Weberian perspectives to examine how digital assets exclude others by creating an ICT wealthy class. Tewathia et al. concluded that exacerbated application of ICT might have amplified the digital divide in India due to socioeconomic inequalities [29]. Another similar study explored the first-level digital divide scenario in Thailand by examining a household ICT usage dataset of 217,217 people [30]. The authors concluded that the affordability of the Internet is the primary reason for the disparity in ICT usages in Thailand, followed by device ownership.

The least-developed South Asian countries such as Bangladesh, Nepal, and Sri Lanka are confronting the digital divide due to lower educational attainment, lower socioeconomic status, lack of motivation, and lack of digital literacy, which drive a vicious cycle of inequality. Zhou et al. analysed survey responses from 500 individuals in Bangladesh, Nepal, and Sri Lanka to investigate determinants of ICT use [31]. The result of the study suggested that higher levels of education are linked to frequent computer use, and South Asian countries are found to fall behind in terms of necessary digital literacy.

Socioeconomic status plays a crucial role in gaining ICT access. Though Bangladesh has recently emerged as a growing economy, people's access to ICT seems progressive. However, according to the most recent statistics, Bangladesh's Internet quality and speed ranked poorest $[32,33]$. According to the overall contexts drawn above, many Bangladeshi students are likely to encounter the digital divide in their e-learning activities amid the COVID-19 pandemic.

\section{Materials and Methods}

The research has been conducted employing mixed methods research where a quantitative survey yielded the primary data. Initially, desk research and a literature review was conducted to get the existing known facts on digital inequalities in Bangladesh and obtain a comprehensive understanding of the multidimensional concept of digital inequality. Then, a structured survey was administrated to collect quantitative data mixed with open-ended questions to collect qualitative information from the student community. The survey was conducted, excluding the identification of respondents to ensure data privacy and research integrity. The student community engaged in higher education (post-secondary) was the target population, regardless of gender. There were 25 questions in the survey designed to get specific data regarding internet access and ownership of devices like personal computers and smartphones-some of the questions were designed to collect data about ICT engagement and usages pattern. Both English and Bengali were used amalgamated to prepare the questionnaire to make the survey understandable to the Bangladeshi student community. As the survey was conducted amid the lockdown, the only way was conducting through online submission. Therefore, a google form was designed to collect data, but there was a critical concern that only people having internet access and computer/smartphone would be able to participate, while the study aims to investigate the digital divide.

Nevertheless, the study focused on identifying the disparity regarding ICT access. Snowball method was applied to resolve the issue, first various student community was determined from the Facebook group through different known communities of the authors. Then, they were requested to engage their friends, who are the potential target people. Some volunteer groups assisted in organising necessary ICT access for the interested participant lacking device and Internet to respond to the survey. After providing consent, 123 students from five different educational levels, 15 age groups, and four different geographic areas responded to the survey. Based on the data volume, Microsoft Excel was used to analysing the quantitative data. Students were informed about the purpose of the study before beginning and asked to provide consent to proceed with the Google Form. 
The majority of respondents $(82.1 \%)$ were college/diploma students, while $13 \%$ were undergrad, $2.4 \%$ were postgraduate, and $2.4 \%$ were either completed or continuing secondary school. The highest number of respondents lives in the rural area $(47.2 \%)$. Whereas $25.2 \%$ of respondents live in the city, $23.6 \%$ in the urban region, and $4.1 \%$ in the small-town, participants' demographic information is shown in Table 1. Although the participants from the rural region have been oversampled, it aids in the generation of valid statistical inferences about the possibly disadvantaged students from the rural area.

Table 1. Respondent student's demography, ICT access, and e-learning activities overview $(\mathrm{N}=123)$.

\begin{tabular}{|c|c|c|}
\hline Variable & Response/Range & Percentage \\
\hline \multirow{5}{*}{ Level of Study } & Postgraduate & $2.4 \%$ \\
\hline & Undergrad & $13 \%$ \\
\hline & College/Diploma & $82.1 \%$ \\
\hline & Secondary School Completed & $0.8 \%$ \\
\hline & Secondary School & $1.6 \%$ \\
\hline \multirow{4}{*}{ Residency Region } & Divisional City & $25.2 \%$ \\
\hline & Small Town & $4.1 \%$ \\
\hline & Urban & $23.6 \%$ \\
\hline & Rural & $47.2 \%$ \\
\hline \multirow{3}{*}{ Age } & 16-18 Years & $54.4 \%$ \\
\hline & 19-23 Years & $38.2 \%$ \\
\hline & 24-30 Years & $7.2 \%$ \\
\hline \multirow{4}{*}{$\begin{array}{l}\text { Student's Smartphone } \\
\text { Ownership Status }\end{array}$} & Students have a personal smartphone & $86.2 \%$ \\
\hline & $\begin{array}{l}\text { Students use smartphones owned by family } \\
\text { members }\end{array}$ & $8.1 \%$ \\
\hline & $\begin{array}{l}\text { The family member has a smartphone, but the } \\
\text { student does not have access }\end{array}$ & $3.3 \%$ \\
\hline & $\begin{array}{l}\text { Neither student nor his family member has access } \\
\text { to a smartphone }\end{array}$ & $2.4 \%$ \\
\hline \multirow{4}{*}{$\begin{array}{c}\text { Student's Personal } \\
\text { Computer (PC) access } \\
\text { status }\end{array}$} & Students have PC & $44.7 \%$ \\
\hline & Students do not have access to PC. & $43 \%$ \\
\hline & Students have access to family member's PC & $9.8 \%$ \\
\hline & $\begin{array}{l}\text { Students' family has PC, but they do not have } \\
\text { access to that }\end{array}$ & $2.4 \%$ \\
\hline \multirow{4}{*}{$\begin{array}{l}\text { Student's Access to the } \\
\text { Internet }\end{array}$} & Students have adequate Internet access $24 \times 7$ & $26 \%$ \\
\hline & Students have sufficient access on demand & $37.4 \%$ \\
\hline & Students have limited access to the Internet & $35 \%$ \\
\hline & Students do not have access to the Internet at all & $1.6 \%$ \\
\hline \multirow{5}{*}{$\begin{array}{l}\text { Students join online } \\
\text { classes }\end{array}$} & Can attend all the online classes & $32.5 \%$ \\
\hline & Can attend most of the class but not all & $20.3 \%$ \\
\hline & Can attend some of the classes & $30.9 \%$ \\
\hline & Can attend a few classes rarely & $3.3 \%$ \\
\hline & Can attend none of the online classes & $13 \%$ \\
\hline
\end{tabular}


Table 1. Cont.

\begin{tabular}{|c|c|c|}
\hline Variable & Response/Range & Percentage \\
\hline \multirow{6}{*}{$\begin{array}{l}\text { The student identified } \\
\text { as the critical barrier to } \\
\text { join online classes }\end{array}$} & $\begin{array}{l}\text { Expensive mobile data package as most of the } \\
\text { student's use cellular data }\end{array}$ & $34.1 \%$ \\
\hline & Weak signal of the cellular Internet network & $39.8 \%$ \\
\hline & $\begin{array}{c}\text { Do not have adequate access to the device (PC, } \\
\text { Smartphone) }\end{array}$ & $10.6 \%$ \\
\hline & Due to not having access to the Internet & $2.4 \%$ \\
\hline & $\begin{array}{c}\text { Other Destruction (Remiss, Personal Issue, Not } \\
\text { Feeling Interesting) }\end{array}$ & $4 \%$ \\
\hline & $\begin{array}{l}\text { Engaged in Job during COVID-19 and not } \\
\text { attending the online class }\end{array}$ & $1.6 \%$ \\
\hline
\end{tabular}

\section{Results}

\subsection{Dependency on Mobile Internet and Price of Internet Package Is Driving the Digital Divide}

Survey data suggest that most students had access to the Internet and device. However, only $32.5 \%$ of respondents said they could always attend their online classes seamlessly, $20.3 \%$ said they could most of the time, and $30.9 \%$ said they could join sometimes. On the other hand, the percentage of the students who are unable to join and rarely join are 13 and $3.3 \%$, respectively. It portrays that the majority of students experienced impediments to taking part in online learning activities. This scenario seems to be more complex than the usual digital divide. The data show a critical relationship between online class attendance and ICT access status. Many of the students stated that despite having an Internet connection and device, they could not always keep internet subscriptions for the high price of the internet package. The scenario implies that the dearth of ICT diffusion is not resisting students to join the online class. Proportionally, most of the students relied on mobile Internet, which was costly and interrupted participation in online classes. The data exhibited that inexpensive broadband Internet has not widely spread among the student community. According to the data, $73.2 \%$ of students used mobile/cellular networks to access the Internet, $25.2 \%$ of students used wired or wireless dedicated/shared internet connectivity, and $1.6 \%$ reported that they are entirely disconnected. Dependency on mobile Internet, and subscription costs has submerged the students into a new dimension of the first-level digital divide. The contemporary BTRC (Bangladesh Telecommunication Regulatory Commission) census shows (Figure 1) that among 108.19 million internet subscribers in Bangladesh, $92.08 \%$ of them use Mobile Internet, which is dominant over cheap broadband internet service [34]. Compared with yield information and BTRC data, the respondents seem representative as both datasets indicate the mobile Internet dependency.

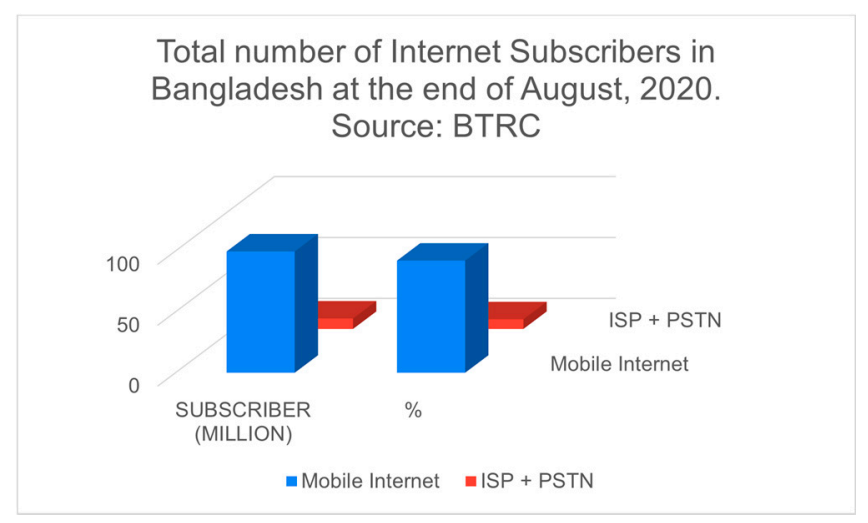

Figure 1. Internet subscribers in Bangladesh and access type. 
Critical analysis of the data revealed a complex relationship that identifies the firstlevel digital divide, illustrated in Figure 2. Considering Internet access, $98.4 \%$ of students said they could arrange it, which seems adequate. Additionally, $86.2 \%$ of students reported they own smartphones, and $44.7 \%$ have PC. However, a substantial number of students could not join e-learning activities, and $34.1 \%$ of them claimed that data price was a significant barrier. Physical access and device availability became futile due to high Internet prices. Likewise, a study on prosperous and technologically advanced countries also found the first-level digital divide remaining due to ongoing expenses to maintain access and devices, where the Internet penetration rate was universal [14]. Therefore, it is not difficult to anticipate that Bangladeshi students are confronting the first-level digital divide although they gained device ownership. Consequently, they are being deprived of e-learning activities resulting in an emerging educational inequality. Perhaps the COVID-19 pandemic exacerbated the disparity.

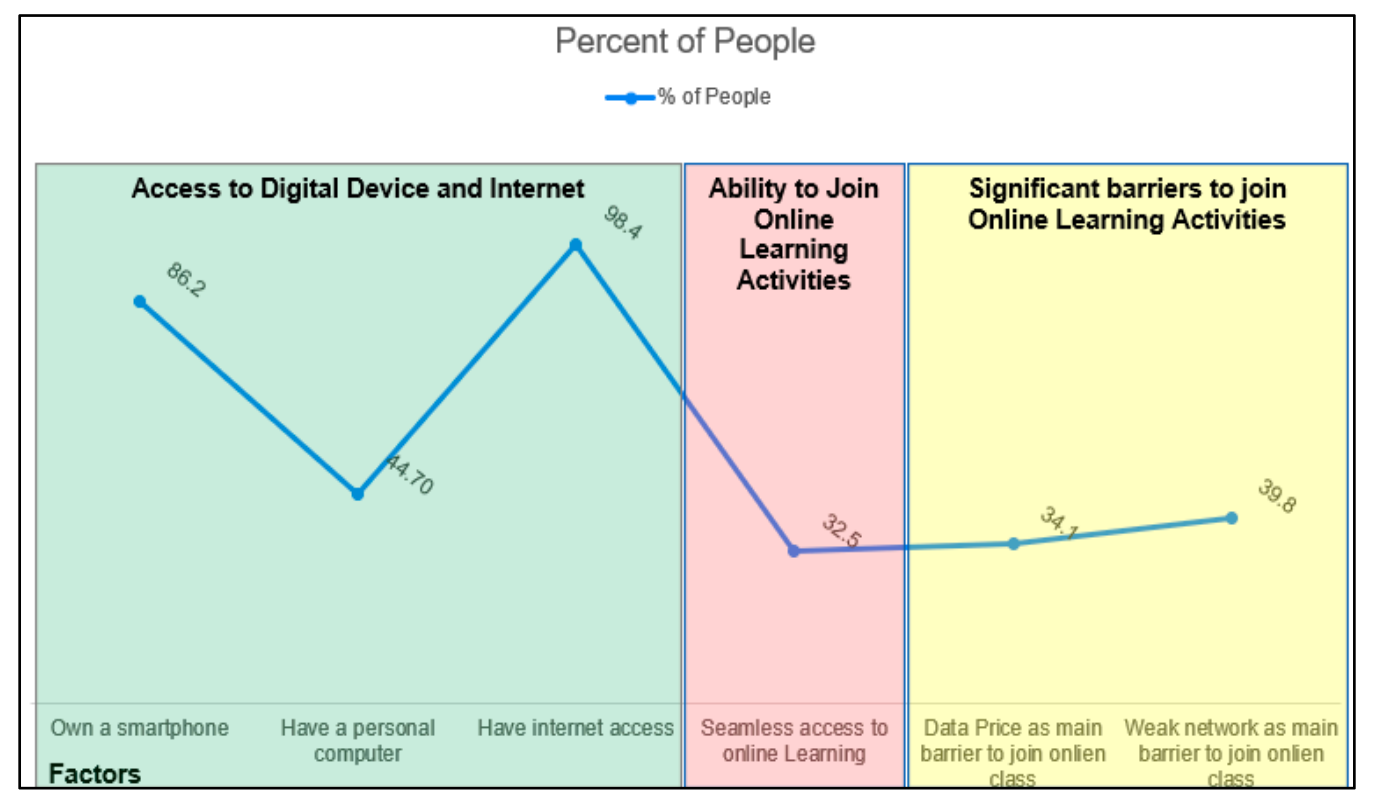

Figure 2. Access to a digital device, joining the online class, and the barrier to seamless access.

\subsection{Inadequate Mobile Network Infrastructure and Poor Signal in Rural Area Is a} Significant Driver

According to the contemporary concept of digital disparity, differentiation in accessing quality Internet is an emerging dimension in the first-level digital divide [11]. At the outset, having access or not having access was a binary concept of the divide. However, profound research suggests that the digital divide is almost an ever-evolving phenomenon that keeps inducing new dimensions as technological progress is an ever-evolving process $[9,10,15]$. Van Dijk and Jan A.G.M studied the achievement and shortcomings in digital divide research in 2006 [9]. Their study revealed that gradually research work identified the mitigation of some divides as the access gap was bridged, but many new concepts of divide appeared. Still, the new metaphor of the digital divide is emerging like "Lack of Skill" or "Lack of Motivation" [9]. The authors concluded that research on the digital divide should be a simultaneous task with technological progress as many new formations have been identified. Similarly, we found that access quality is a significant driver of the digital divide among Bangladeshi students.

Remarkably, the network quality of mobile Internet has been reported as one of the most destructive issues driving access quality and resulting in the first digital divide. Comparatively, students from rural regions confronted amplified barriers regarding network signal quality. According to our study, $47 \%$ of students from rural areas identified weak network signals as the main barrier to join e-learning, whereas 35\% of their counterparts 
from the city and urban areas reported network quality issues shown in Figure 3. Moreover, poor mobile network quality seems another dominant driver of the digital divide as most students depend on cellular mobile internet service. The demography of the Internet users in Bangladesh supports our findings as $92.08 \%$ of internet subscribers use Mobile Internet [10].

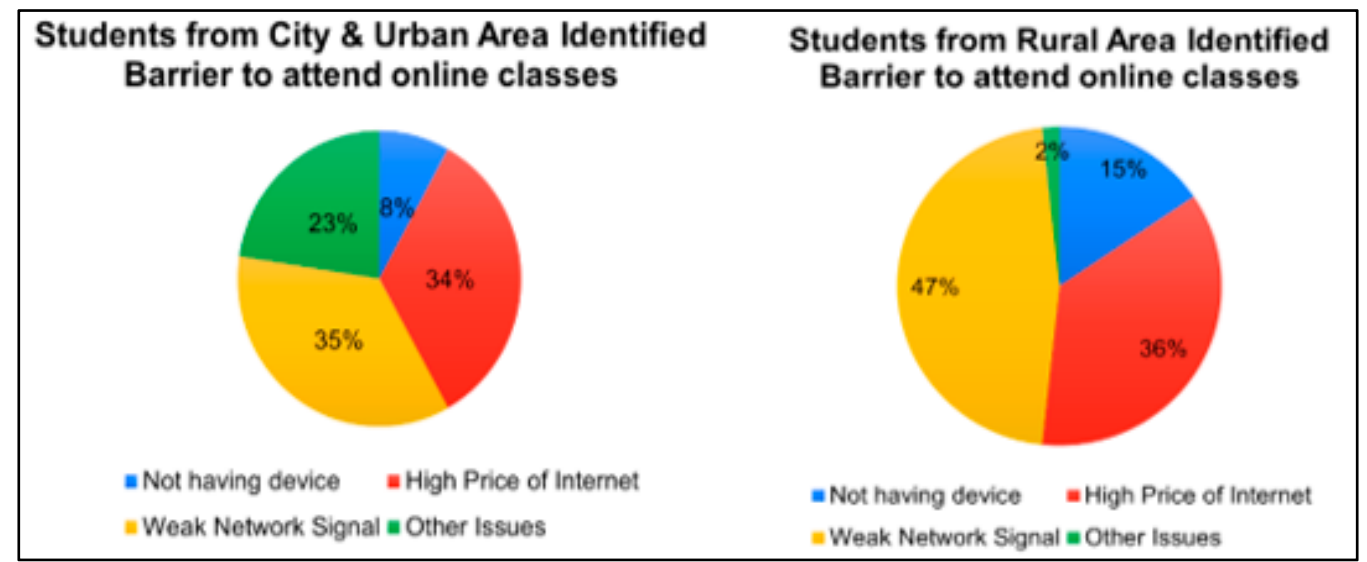

Figure 3. Barriers to joining online classes in different geographic regions.

Consequently, despite having sufficient access to digital devices, many students remained out of the online classrooms. There is empirical evidence that the network access quality fosters the digital divide [11,12]. In recent days Internet penetration and availability of devices have been notably boosted in Bangladesh. However, the quality of the network remained as the latent digital divide driver exposed during the emphasised online learning during COVID-19.

\subsection{Students from Rural Region Likely to Face Discrimination to Access Online Class}

While the wealthy can continue their online schooling during the coronavirus pandemic, low-income rural children cannot do so because of a lack of infrastructure and amenities. According to the Bangladesh Ministry of Education, 76\% of the country's secondary schools are located in rural communities. In addition, approximately $60 \%$ of primary school students attend government-run schools, mostly in rural areas.

An independent study by a South Asian NGO (SANEM) stated, "Rural schools lack infrastructure including digital equipment, qualified teachers and hygiene facilities. [35]" The author claimed that rural schools are comparatively underprivileged to deal with the pandemic situation. Meanwhile, Bangladeshi private schools have quickly adopted online learning methods after the outbreak, using social media platforms like Facebook and YouTube to deliver lectures. Generally found in urban cities, these private schools serve the upper classes. These schools are better equipped and prepared, and the students have access to technology because their parents are also from upper social strata and likely to have moderate or advanced digital literacy. In a recent study conducted by BRAC, the organisation found that over half of Bangladesh's rural households lacked access to the Internet. We also found that rural students are falling behind in accessing online classes.

There is an explicit deviation in online class participation patterns between the students from the rural and city-urban areas. Analysing quantitative data, we revealed that $62.5 \%$ of the students who could attend online classes are from rural areas (Figure 4 ). Twice as many students in rural areas were out of online classes compared to city and urban students, the regional attendance pattern shown in Figure 5. 


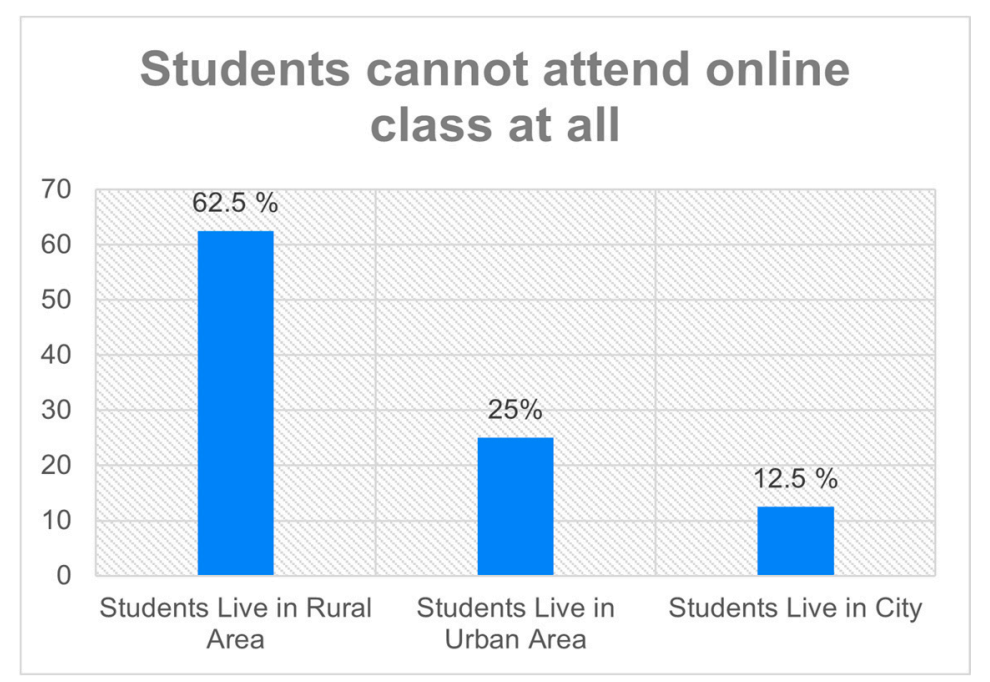

Figure 4. Distribution of students who cannot join any online learning activities based on location.

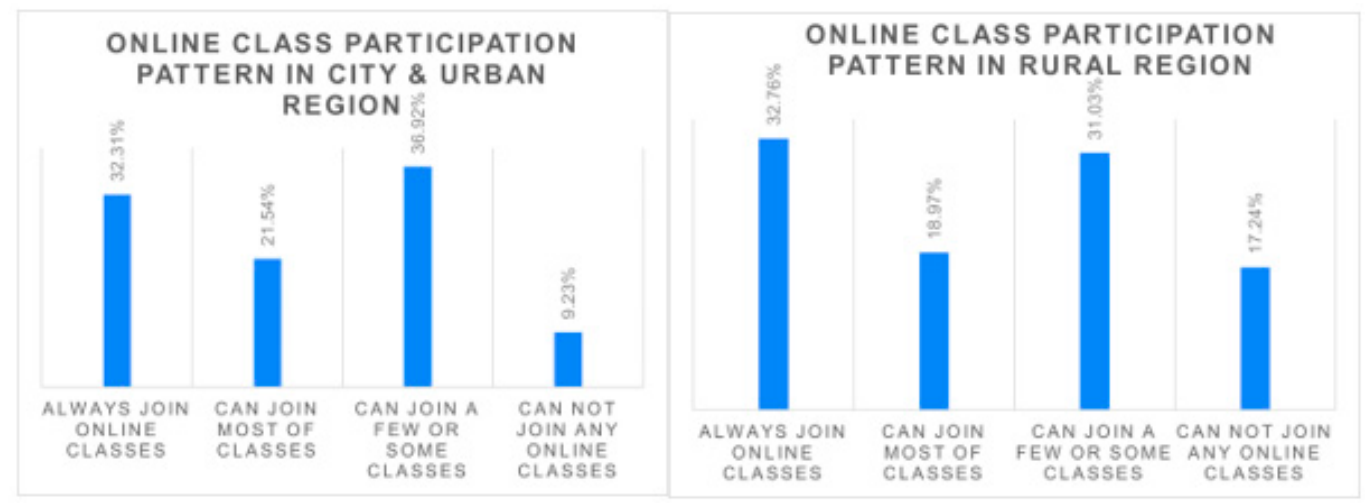

Figure 5. Participation pattern in online classes based in a different location.

\subsection{Pandemic Increased Digital Distraction Which Is Resulting Third Level Digital Divide}

Many recent studies probed the second and third-level digital divides. The digital divide moves from the first-level access divide to the second-level skill gap, and the disparity of outcomes from ICT usages is defined as the third digital divide [36]. After having sufficient access to ICT, not everybody can gain equal outcomes. The gain depends on the ICT skills and usage pattern of an individual. For instance, some research has found that economically backward individuals spend more time on the Internet [37,38]. The outcomes of using ICT are not guaranteed by spending more time with ICT; it depends on how and why a person uses ICT [39]. In this study, the students who spend more time with ICT found media vulnerable as they were overusing ICT for social networking and entertainment purposes. We identified some cases of ICT usages harming their study while the COVID-19 pandemic exacerbated ICT usage. According to the respondents, $50.04 \%$ of students used social media most of the time, $21.95 \%$ used ICT frequently for entertainment purposes, and $26.83 \%$ used ICT mainly for study purposes, illustrated in Figure 6 . During the lockdown, 52.8\% of participants strongly agreed that the COVID-19 pandemic scenario had spurred them to increase their use of smartphone, computers, and the Internet. However, $51 \%$ of the participants expressed anxiety about excessive ICT usage is devastating for their study, and $50.4 \%$ anticipated adverse effects on health. 


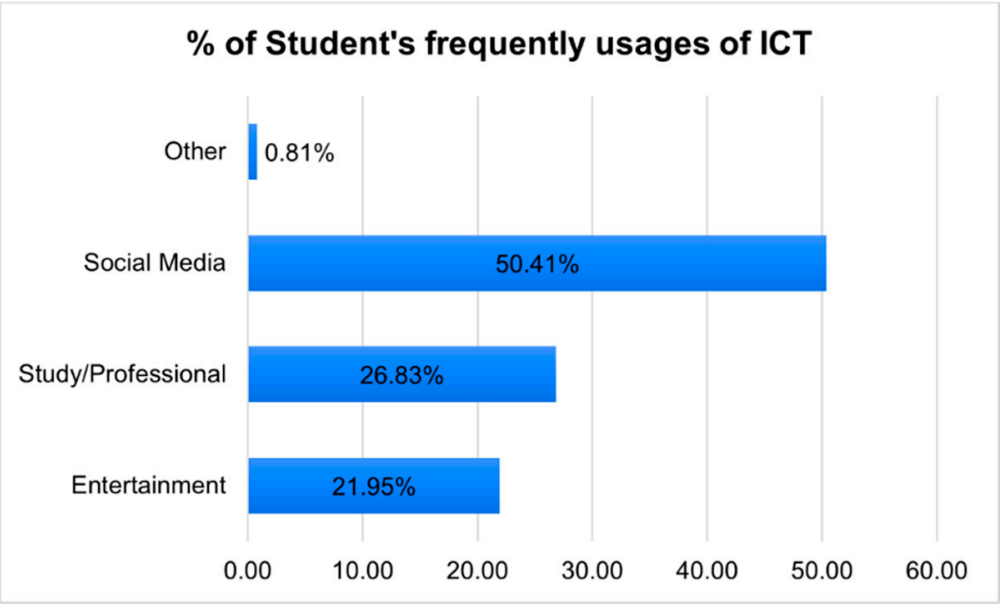

Figure 6. Most frequently, usage of ICT by students during the COVID-19 pandemic.

Some students who do not have a reliable internet connection or access to technology find it difficult to participate in e-learning; this gap occurs across countries. For example, the percentage of students in Norway, Switzerland, and Austria with a computer to use in the classroom is higher than the percentage of students in Indonesia, which is lower in that country (compared to the OECD average).

Evidently, we sought that the COVID-19 pandemic increased ICT usages. As a result, gradually, students adopted ICT to get into the online trend. However, the difference in ICT usage will cause different outcomes, which results in the third level of the digital divide considering the usage pattern of ICT by the Bangladeshi students' community comprehensively illustrated in Figure 7.

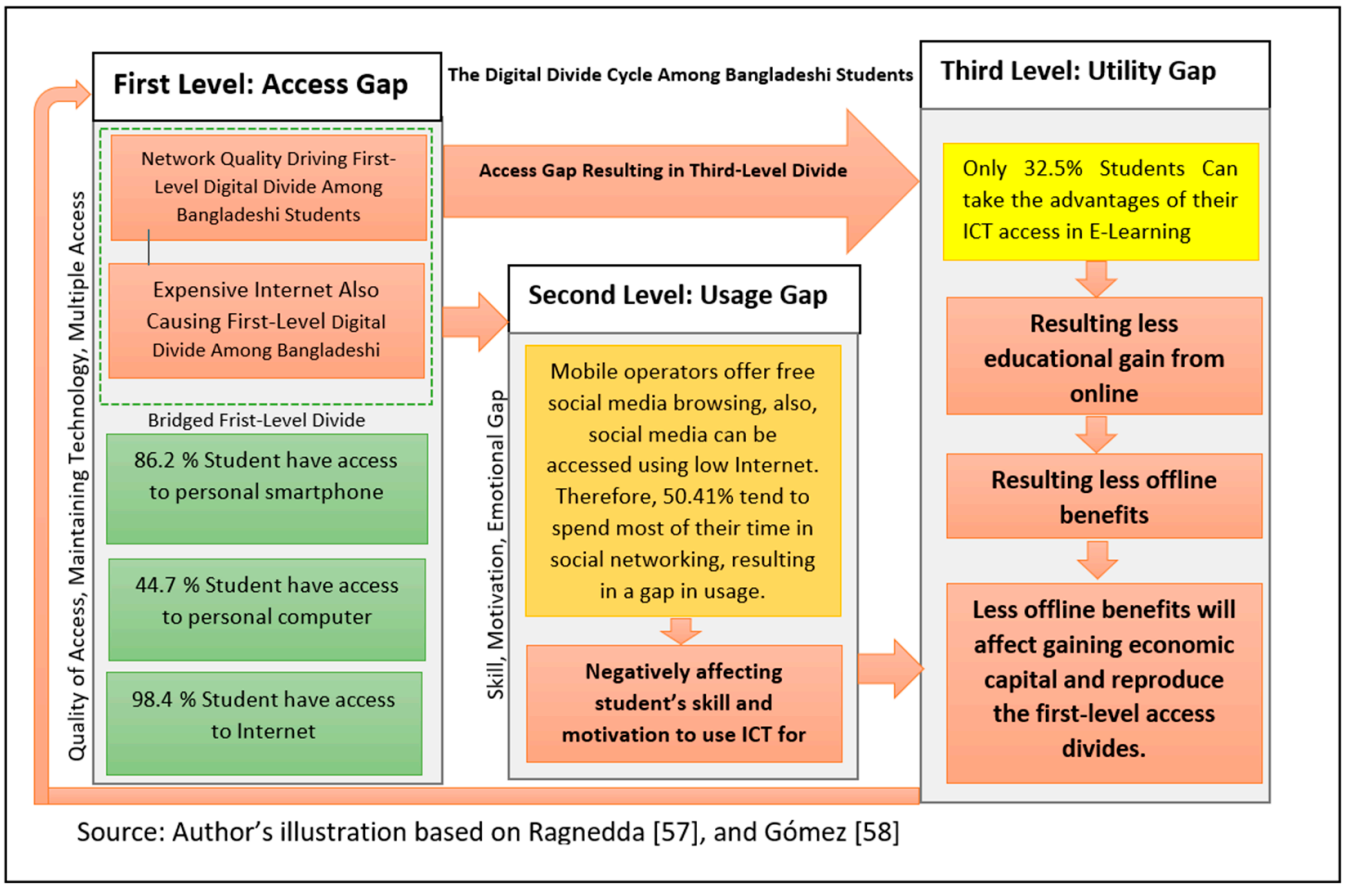

Figure 7. Illustration of digital divide among Bangladeshi students based on multi-level digital divide and bidirectional capital conversion theories.

\section{Conclusions}

In this study, we have tried to explore multidimensional digital divides among the Bangladeshi students experienced in e-learning activities during the COVID-19 pandemic, and the leading drivers of the divide addressed in RQ1 and RQ2. We examined the yield 
data thoroughly and produced some critical statistical inferences in this article. We also synthesised the results using prominent theoretical frameworks of the digital divide. The students are likely to be submerged in a vicious cycle of digital divides, illustrated in Figure 7. Although most students possess physical access to ICT, a complex first-level digital divide still exists. Consequently, excluded students fail to gain knowledge using their physical access for e-learning, resulting in a third-level digital divide [15]. According to the bidirectional capital conversion theory, less gain from online capital (access to ICT, skill, utility) results in less gain offline capital (economic, social, cultural) [10]. Likewise, less offline capital will narrow down the opportunity to access ICT, which has constructed a vicious cycle of the digital divide. This kind of effect may take a long time to be manifested; however, profound research warned this consequence.

The critical finding reflects that pandemic increased digital disparity. The issues addressed in RQ1 have been identified that a significant number of students are deprived of online learning activities, students from rural areas are more likely to face inequalities to access online classes. Despite having access to digital devices, the high cost of internet packages and dependency on mobile Internet is driving the digital divide. According to our study, $98 \%$ of students reported they have access to devices and can arrange internet connection, but they cannot afford it. Therefore, availability is enough, but affordability is another critical barrier. Inadequate mobile network infrastructure and poor signal quality in rural areas are significant drivers of the digital divide during the COVID-19 pandemic. Almost twice the number of students in a rural area could not join the online classes compared with students from cities. Digital disruption has become an alarming concern. Students spend more time on social media or for amusement rather than utilising ICT for academic purposes, leaving them media vulnerable.

The study was carried out during the strict lockdown period at the research site. Therefore, reaching a large sample was tough. We anticipate the number of samples as the limitation of our study. Nevertheless, many contemporary newspapers reported that a large number of students are deprived of e-learning amid the COVID-19 pandemic in Bangladesh; the UN report also found exacerbated digital divide in developing countries concerning e-learning [21]. We found the results valid from multiple theoretical explanations, although reaching more respondents was a constraint.

Concerning the findings, we strongly suggest that the respective stakeholders should immediately take account of the internet cost issues and reduce the price for the student with swift action and policy development. Besides, the broadband internet connection should be considered and improve the existing mobile network in rural areas. Along with that, parents and teachers need to take care of students for their digital wellbeing. Moreover, to understand a comprehensive scenario and resolve the nationwide problems, further research is essential by the government and the internet service provider's side. We strongly suggest extensive nationwide research, including a large sample, to rigorously examine the divides and prevent emerging digital divide-driven educational inequalities among Bangladeshi students.

Author Contributions: M.B. devised the study, formulated the research question, and reviewed existing literature; M.B. and M.M.R. designed research methodology and performed data collection and data analysis; M.B. visualised the data. M.B. and M.I.I.R. prepared the first draft, M.I.I.R. assisted in validating the findings. M.R. supervised the process, reviewed the draft manuscript, and advised necessary corrections. Proofreading is finally performed with the intention of detecting and eliminating errors such as typographical and grammatical inaccuracies by M.B. and M.M.R. All authors have read and agreed to the published version of the manuscript.

Funding: The study has been conducted from the self-initiative of the authors without any external funding.

Data Availability Statement: The data regarding this study has been securely stored following research integrity and data management rules; the corresponding author can provide them with needs. 
Acknowledgments: We are thankful to Jung-Sook Lee, the faculty member of the school of social science at UNSW, Sydney, Australia. She provided her valuable opinion while designing the survey questionnaire. We apricate and accolade her effort to help the authors design the survey questionary as an expert on this research area. This research was undertaken while corresponding author Md Badiuzzaman was waiting to be enrolled in UNSW, and according to Bangladesh's human ethics expectations and standards. Author Md Badiuzzaman is now affiliated with UNSW, Sydney, Australia.

Conflicts of Interest: The authors declare that there is no conflict of interest.

\section{References}

1. Huang, C.; Wang, Y.; Li, X.; Ren, L.; Zhao, J.; Hu, Y.; Zhang, L.; Fan, G.; Xu, J.; Gu, X.; et al. Clinical features of patients infected with 2019 novel coronavirus in Wuhan, China. Lancet 2020, 395, 497-506. [CrossRef]

2. Islam Rabby, M.; Hossain, F.; Al Islam, M.; Sadrul Islam, A.M.; Akhi, I.; Huda, S. Clinical management and suggested treatment for COVID-19 in the Indian sub-continent: A comparative study. Curr. Med. Res. Pract. 2020, 10, 230. [CrossRef]

3. Bangladesh COVID. Available online: https://www.worldometers.info/coronavirus/country/bangladesh/ (accessed on 30 June 2021).

4. Rabby, M.I.I.; Hossain, F. Study of ongoing registered clinical trials on covid-19: A narrative review. Sao Paulo Med J. 2020, 138, 441-456. [CrossRef]

5. Cohen, M.Z.; Phillips, J.M.; Palos, G. Qualitative research with diverse populations. Semin. Oncol. Nurs. 2001, 17, 190-196. [CrossRef] [PubMed]

6. Hoffman, D.L.; Novak, T.P.; Schlosser, A.E. The evolution of the digital divide: Examining the relationship of race to Internet access and usage over time. In The Digital Divide: Facing a Crisis or Creating a Myth; The MIT Press: Cambridge, MA, USA, 2001; pp. 47-98. Available online: http:/ / books.google.es/books?hl=en\&lr=\&id=MbareJicwKAC\&oi=fnd\&pg=PA47\&dq=The+ evolution+of+the+digital+divide:+Examining+the+relationship+of+race+to+internet+access+and+usage+over+time.\&ots=B Dmr4kgIi\&sig=ZFd9q3jSFNeijzz2O7a-5LC6vf0 (accessed on 30 June 2021).

7. Tarman, B. The Digital Divide in Education. Online Submiss. 2003; p. 28. Available online: https://eric.ed.gov/?id=ED508213 (accessed on 30 June 2021).

8. Chipeva, P.; Cruz-Jesus, F.; Oliveira, T.; Irani, Z. Digital divide at individual level: Evidence for Eastern and Western European countries. Gov. Inf. Q. 2018, 35, 460-479. [CrossRef]

9. van Dijk, J.A.G.M. Digital divide research, achievements and shortcomings. Poetics 2006, 34, 221-235. [CrossRef]

10. Gómez, D.C. The third digital divide and Bourdieu: Bidirectional conversion of economic, cultural, and social capital to (and from) digital capital among young people in Madrid. J. Youth Stud. 2020, 22, 1-18. [CrossRef]

11. Robinson, L.; Schulz, J.; Blank, G.; Ragnedda, M.; Ono, H.; Hogan, B.; Mesch, G.S.; Cotten, S.R.; Kretchmer, S.B.; Hale, T.M.; et al. Digital inequalities 2.0: Legacy inequalities in the information age. First Monday 2020. [CrossRef]

12. Robinson, L.; Schulz, J.; Dunn, H.S.; Casilli, A.A.; Tubaro, P.; Carvath, R.; Chen, W.; Wiest, J.B.; Dodel, M.; Stern, M.J.; et al. Digital inequalities 3.0: Emergent inequalities in the information age. Sociology 2020. [CrossRef]

13. Ragnedda, M.; Laura Ruiu, M. Defining Digital; Emerald Publishing Limited: Bingley, UK, 2020; pp. 9-38.

14. Gómez, D.C. The Three Levels of the Digital Divide: Barriers in Access, Use and Utility of Internet among Young People in Spain. Interações Soc. e Novas Mod. 2018, 34, 64-91. [CrossRef]

15. van Deursen, A.J.A.M.; van Dijk, J.A.G.M. The first-level digital divide shifts from inequalities in physical access to inequalities in material access. New Media Soc. 2019, 21, 354-375. [CrossRef] [PubMed]

16. Ragnedda, M. The Third Digital Divide: A Weberian Approach to Digital In-Equalities; Routledge: New York, NY, USA, 2017.

17. Grazzi, M.; Vergara, S. Internet in Latin America: Who uses it? and for what? Econ. Innov. New Technol. 2014, $23,327-352$. [CrossRef]

18. Mendonca, S.; Crespo, N.; Simoes, N. Inequality in the network society: An integrated approach to ICT access, basic skills, and complex capabilities. Telecommun. Policy 2015, 39, 192-207. [CrossRef]

19. Karakara, A.A.W.; Osabuohien, E.S. Households' ICT access and educational vulnerability of children in Ghana. Cogent Soc. Sci. 2019, 5, 1-21. [CrossRef]

20. U.N. Education During COVID-19 and Beyond (August 2020). 2020, pp. 2-26. Available online: https://unsdg.un.org/resources/ policy-brief-education-during-covid-19-and-beyond (accessed on 30 June 2021).

21. Milek, A.; Stork, C.; Gillwald, A. Engendering communication: A perspective on ICT access and usage in Africa. Info J. Policy Regul. Strategy Telecommun. 2011, 13, 125-141. [CrossRef]

22. Lu, M.-T. Digital Divide in Developing Countries. J. Glob. Inf. Technol. Manag. 2014, 6846. [CrossRef]

23. Dewan, S.; Riggins, F.J. The Digital Divide: Current and Future Research Directions. J. Assoc. Inf. Syst. 2005, 6, $298-337$.

24. Zhang, J.; Yang, J.; Chang, M.; Chang, T. Towards a critical understanding to the best practices of ICT in K-12 education in global context. Lect. Notes Educ. Technol. 2016. [CrossRef]

25. World Bank. GDP per Capita (Current US\$) I Data. 2019. Available online: https://data.worldbank.org/indicator/NY.GDP.PCAP. CD (accessed on 30 June 2021).

26. ITU. Statistics. 2020. Available online: https://www.itu.int/en/ITU.D/Statistics/Pages/stat/default.aspx (accessed on 30 June 2021). 
27. Karar, H. Algorithmic Capitalism and the Digital Divide in Sub-Saharan Africa. J. Dev. Soc. 2019, 35, 514-537. [CrossRef]

28. Tewathia, N.; Kamath, A.; Ilavarasan, P.V. Technology in Society Social inequalities, fundamental inequities, and recurring of the digital divide: Insights from India. Technol. Soc. 2020, 61, 101251. [CrossRef]

29. Zhou, Y.; Singh, N.; Kaushik, P.D.; Asia, S. The digital divide in rural South Asia: Survey evidence from Bangladesh, Nepal and Sri Lanka. IIMB Manag. Rev. 2011, 23, 15-29. [CrossRef]

30. Lopez-Sintas, J.; Lamberti, G.; Sukphan, J. The social structuring of the digital gap in a developing country. The impact of computer and internet access opportunities on internet use in Thailand. Technol. Soc. 2020, 63, 101433. [CrossRef]

31. The Daily Star. Mobile Internet Slowest in Bangladesh among 42 Countries. 2020. Available online: https: / /www.thedailystar. net/business/news/mobile-internet-slowest-bangladeshamong-42-countries-1892761 (accessed on 30 June 2021).

32. Ookla. Ranking Mobile and Fixed Broadband Speeds from around the World on a monthly Basis. 2021. Available online: https: / / www.speedtest.net/global-index (accessed on 30 June 2021).

33. Grishchenko, N. The gap not only closes: Resistance and reverse shifts in the digital divide in Russia. Telecommun. Policy 2020, 44, 102004. [CrossRef]

34. BTRC. Internet I BTRC. 2020. Available online: http:/ / www.btrc.gov.bd/telco/internet (accessed on 30 June 2021).

35. Pick, J.; Sarkar, A.; Parrish, E. The Latin American and Caribbean digital divide: A geospatial and multivariate analysis. Inf. Technol. Dev. 2020, 1-28. [CrossRef]

36. COVID-19 Deepens Divide between Bangladesh's Rural and Urban Students. Available online: https://www.dw.com/en/ education-bangladesh/a-55358552 (accessed on 30 June 2021).

37. Han, E.S.; Goleman, D.; Boyatzis, R.; Mckee, A. History, Education, and the Schools. J. Chem. Inf. Modeling 2019, 53, 9.

38. World Internet Stats. Available online: https:/ / www.internetworldstats.com/stats.htm (accessed on 30 June 2021).

39. Chinn, B.M.D.; Fairlie, R.W. The determinants of the global digital divide: A cross-country analysis of computer and internet penetration. Oxford econ. Pap. 2007, 59, 16-44. [CrossRef] 